\title{
O USO DE LÍNGUAS PELA PRIMEIRA GERAÇÃO DE IMIGRANTES OKINAWANOS NA CASA VERDE EM SÃO PAULO ${ }^{1}$ THE USE OF LANGUAGES BY THE FIRST GENERATION OF OKINAWAN IMMIGRANTS IN CASA VERDE IN SAO PAULO
}

Eduardo Nakama ${ }^{2}$ Yûki Mukaì

Resumo: Este trabalho investiga a situação sociolinguística de uso das línguas por dez okinawanos de primeira geração que imigraram para o Brasil e que vivem atualmente no distrito da Casa Verde na capital do estado de São Paulo. Trata-se de pesquisa qualitativa (LÜDKE; ANDRÉ, 1986; SILVA, 2017) do tipo etnográfico (BLOMMAERT, 2006; GREEN; BLOOME, 1997) na modalidade de história de vida (CRUZ NETO, 2002; SAKURAI, 2012). Baseado no conceito de bilinguismo de Grosjean (1982, 2008) e translinguagem (GARCÍA, 2009), foi revelado que os imigrantes de Okinawa, província do Japão, usam mais de uma língua no dia a dia e mudam de uma língua para outra de acordo com o contexto e os interlocutores, mais especificamente, levando em consideração o conhecimento linguístico de seu interlocutor.

Palavras-chave: Imigração. Okinawa. Brasil. Bilinguismo. Uchināguchi.

Abstract: This paper investigates the sociolinguistic situation of the use of languages by ten first generation Okinawans who immigrated to Brazil and currently live in the district of Casa Verde in the capital of the state of Sao Paulo. It is a qualitative research (LÜDKE; ANDRÉ, 1986; SILVA, 2017), using the ethnographic approach (BLOMMAERT, 2006; GREEN; BLOOME, 1997) and focusing on the life history method (CRUZ NETO, 2002; SAKURAI, 2012). Based on the Grosjean's concept of bilingualism $(1982,2008)$ and translanguaging (GARCÍA, 2009), it was

1 Artigo submetido em 10/ 08/2020 e aceito em 20/10/2020.

2 Graduado em Letras-Japonês pela Universidade de Brasília. e_nakama@yahoo.com ORCID iD: https:// orcid.org/0000-0002-0300-8193

3 Doutor em Linguística Aplicada. Professor Associado do Instituto de Letras da Universidade de Brasília.yuki@unb.br ORCID iD: https://orcid.org/0000-0001-9618-7743 
revealed that immigrants from Okinawa, province of Japan, use more than one language daily and change from one language to another according to the context and the interlocutors, more specifically, the linguistic knowledge of their interlocutor.

Keywords: Immigration. Okinawa. Brazil. Bilingualism. Uchināguchi.

\section{INTRODUÇÃO}

Este trabalho tem como objetivo investigar a situação sociolinguística de uso de línguas pelos okinawanos ${ }^{4}$ de primeira geração que imigraram para o Brasil e que vivem atualmente no distrito da Casa Verde na capital do estado de São Paulo.

A imigração de okinawanos iniciou em 1900 para o Havaí, nos Estados Unidos. Em seguida, os okinawanos imigraram para diversos locais no mundo, como México e Filipinas (1904), Nova Caledônia (1905), Peru (1906), Canadá (1907) e Brasil (1908) (PIRES, 2016, p. 76).

Para o Brasil, a imigração de japoneses inicia-se em 1908. O primeiro navio, o Kasato Maru, transportou 781 imigrantes, saindo do porto de Kōbe em 28 de abril de 1908 e chegou no porto de Santos em 18 de junho do mesmo ano. Desses imigrantes, cerca de 325, ou seja, mais de 40\%, vieram de Okinawa (MORIMOTO, 2012). De 1908 até 2000, aproximadamente 25.000 pessoas imigraram de Okinawa para o Brasil.

Atualmente, o Brasil tem uma população de cerca de 1,5 milhão de descendentes de japoneses (nikkei), dos quais aproximadamente 150 mil, isto é, 10\%, têm raízes em Okinawa (MORIMOTO, 2012). Em Okinawa, hoje o ensino e uso da língua japonesa fizeram com que as línguas originárias do reino de Ryūkyū $\bar{u}^{5}$ (uchināguchi $i^{6}$, entre outras) fossem usadas apenas em conversas entre alguns idosos e em apresentações teatrais e musicais típicas da região. Por outro lado, no Brasil, alguns okinawanos não mantêm contato com japoneses de outras províncias e, por esse motivo, diferentemente de Okinawa, conseguiram preservar sua língua e cultura sem receber forte influência da língua e da cultura japonesas. A associação das pessoas originárias de Okinawa ${ }^{7}$ é formada por 44 filiais no Brasil. Cabe destacar que é a única associação de província do Japão a possuir filiais. Possui cerca de 3.000 famílias associadas no Brasil e é a maior associação de província no país (MORIMOTO, 2012).

Segundo Moseley (2010), as línguas originárias do reino de Ryūkyū estão em risco de extinção e, hoje em dia, quase não há crianças aprendendo-as como primeira língua (língua materna). Portanto, os imigrantes de Okinawa no Brasil, como continuaram a usar sua língua materna no dia a dia (MORI, 2018), representam uma comunidade

4 Aqueles que são da província de Okinawa, no Japão.

5 O antigo reino de Ryūkyū localiza-se atualmente ao sul da península coreana, a leste da China, ao norte das Filipinas, na porção extrema sudoeste do Japão. O arquipélago de Ryūkyū é uma cadeia de ilhas japonesas que se estendem a sudoeste de Kyūsyū e a maior é a ilha de Okinawa.

6 Língua de Okinawa.

7 Associação Okinawa Kenjin do Brasil. 
muito importante para o estudo dessas línguas em risco de extinção. É natural que essa população de imigrantes esteja ficando idosa e seu número esteja diminuindo, uma vez que não há mais imigração de Okinawa para o Brasil. Com base nesses fatos faz-se premente o conhecimento da situação linguística desses imigrantes.

Diante do exposto, foi proposta a seguinte pergunta para atingir o objetivo supracitado: Quais as línguas e em que contexto os imigrantes de primeira geração de Okinawa as usam no dia a dia no Brasil?

\section{FUNDAMENTAÇÃO TEÓRICA}

\subsection{Imigração de Okinawa para o Brasil}

Primeiramente, vê-se a evolução quantitativa de emigrantes okinawanos do ano de 1900 até o ano de 1981 (vide figura 1). Antes da Segunda Guerra Mundial, houve diversos picos de número de emigrantes okinawanos com mais de 4.000 pessoas, enquanto em outros anos não chegaram a 1.000. Isso se deu devido às mudanças legislativas nos países de destino ${ }^{8}$ e à Primeira e à Segunda Guerra Mundial. Os principais destinos dos okinawanos foram Havaí, Sudeste Asiático e América do Sul. No entanto, após a Segunda Guerra Mundial, a imigração okinawana concentrou-se nos países da América do Sul (sobretudo, o Brasil, a Argentina e a Bolívia) por questões da geopolítica mundial ${ }^{9}$ (ISHIKAWA, 2005, p. 17).

Figura 1 - Quantidade de okinawanos que emigraram antes e depois da Segunda Guerra Mundial

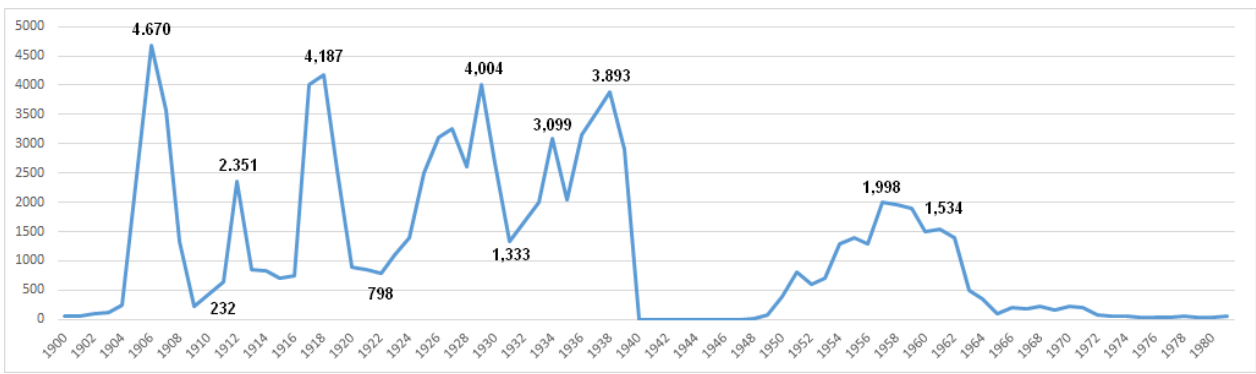

Fonte: Okinawa Dai Hyakka Jiten

(OKINAWA DAI HYAKKA JITEN KANKŌ JIMUKYOKU-HEN, 1983)

8 Aqui citamos três exemplos: (1) Em 1908, a imigração para o Havaí foi restringida devido ao movimento anti-japonês; (2) Em 1924, o governo brasileiro decidiu abolir o subsídio de despesas de viagem para imigrantes japoneses. No mesmo ano, o governo japonês, que incentivava a emigração devido ao Grande Terremoto de Kantō de 1923, passou a arcar com todas as despesas de viagem ao invés do governo brasileiro; (3) Com o número crescente repentino de imigrantes japoneses para o Brasil devido à Grande Depressão em 1929, o Congresso Nacional do Brasil aprovou a legislação referente à restrição de imigrantes japoneses em 1934. Quanto aos detalhes, vide Ishikawa (2005).

9 Por exemplo, o governo de Ryūkyū estabeleceu o plano de imigração para a Bolívia com auxílio financeiro dos EUA. 
A partir de agora, focar-se-á a imigração okinawana na América do Sul após $1948^{10}$ (vide figura 2 a seguir).

Para a Argentina houve um pico de 653 pessoas no ano de 1951, diminuindo progressivamente desde então. A imigração para a Bolívia iniciou em 1948, com maior concentração entre os anos de 1958 e 1962. O Brasil, por sua vez, teve um pico em 1957, ultrapassando 1.000 pessoas, diminuindo significativamente a partir de 1963. De 1908 até 2000, aproximadamente 25.000 pessoas imigraram de Okinawa para o Brasil.

Figura 2 - Quantidade de imigrantes okinawanos por país da América Latina (de 1948 a 1972)

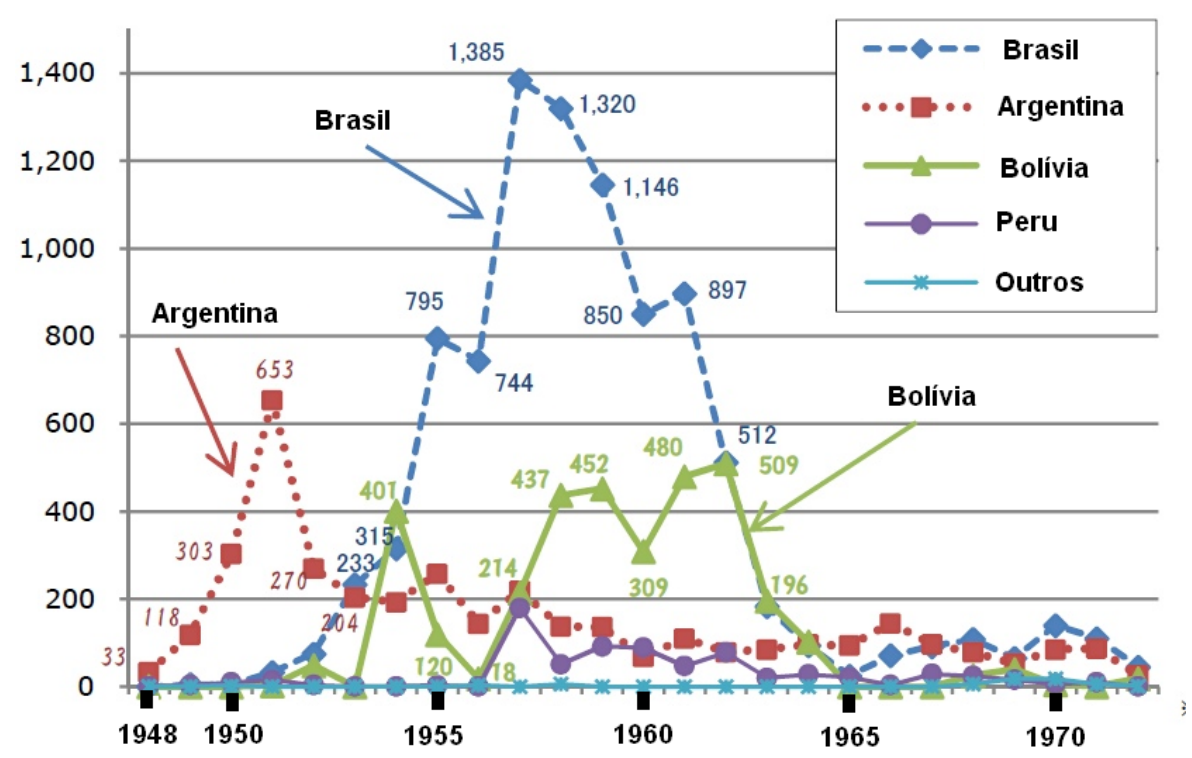

Fonte: Okinawa-ken Kōryū Suishin-ka, s.d. ${ }^{11}$

Percebe-se que, tanto na figura 1 quanto na figura 2, após a década de 1960, ocorreu uma queda significativa quanto à quantidade de imigrantes okinawanos para todos os países porque houve um esforço para a reconstrução de Okinawa. Além disso, nesse período, entre os anos de 1954 e 1973, conhecido como milagre econômico japonês, precisou-se internamente de muitos trabalhadores e, por isso, não foi necessária a promoção de emigração para o exterior (ISHIKAWA, 2005, p. 18).

10 Conforme mostra a figura 1 deste artigo, houve a imigração okinawana mesmo antes desse ano. Quanto aos detalhes, vide Ishikawa (2005).

11 Disponível em: https:/www.pref.okinawa.jp/toukeika/so/topics/topics457.pdf. Acesso em: 14 de dezembro de 2018. 


\subsection{Língua "uchināguchi”"}

Uchināguchi é o nome local para se referir à língua falada na ilha de Okinawa, ilha principal do arquipélago homônimo. Uchinā é o nome local para Okinawa.

A língua de Okinawa é, na verdade, uma das línguas ryukyuanas (vide nota 5) que são línguas japônicas, provavelmente derivadas do proto-japonês ${ }^{12}$. Heinrich, Miyara e Shimoji (2015) reconhecem cinco línguas distintas no arquipélago de Ryūkyū: a língua de Amami, a língua de Okinawa, a língua de Miyako, a língua de Yaeyama e a língua de Yonaguni. Segundo os mesmos autores (2015),

As ilhas de Ryūkyū são extremamente ricas em diversidade linguística. Dialetos regionais ryukyuanos uma vez diferiam de ilha para ilha, de vila para vila, de bairro para bairro, mas muitas dessas variedades desapareceram. Elas tornaram-se extintas como um efeito de nivelamento de dialeto que foi desencadeado por mudanças sociais e comunicativas nas comunidades ryukyuanas. Não há nenhuma variedade padrão de qualquer das línguas ryukyuanas. Nunca existiu uma variedade padrão, apesar do fato de o okinawano de Shuri ter sido uma vez a língua da corte de Ryūkyū e, portanto, continuou a desfrutar de maior prestígio do que qualquer outra variedade ryukyuana até os dias de hoje. (HEINRICH; MIYARA; SHIMOJI, 2015, p.1-2) ${ }^{13}$.

Apesar de os autores (HEINRICH; MIYARA; SHIMOJI, 2015) enfatizarem o desaparecimento de dialetos locais ali falados, é possível observar sua influência social, por exemplo, no fato de existirem muitas associações de imigrantes da província de Okinawa no Brasil, fato atípico em outras associações de imigrantes japoneses de outras províncias. Um dos motivos da existência de várias associações é porque os okinawanos tendem a se juntar em comunidades que falam um mesmo dialeto.

\subsection{Bilinguismo individual}

Existem, em relação ao conceito de bilinguismo individual, duas posições distintas na literatura. A primeira, de Bloomfield (1993), entende o bilinguismo como o "controle

12 Para uma discussão mais detalhada, indicamos a leitura de: PELLARD, T. The linguistic archeology of the Ryukyu Islands, p. 13-37, In: HEINRICH, P.; MIYARA, S.; SHIMOJI, M. Handbook of the Ryukyuan Languages. Berlin: Walter de Gruyter, 2015.

13 Do original: The Ryukyu Islands are extremely rich in linguistic diversity. Ryukyuan regional dialects once differed from island to island, from village to village, and from block to block, but many of these varieties have already vanished. They have become extinguished as an effect of dialect leveling which has been triggered by social and communicative changes in Ryukyuan communities. There exist no variety of any of the Ryukyuan languages. There never existed a standard variety either, despite the fact that Shuri Okinawan was once the language of the Ryukyuan Court and thus has continued to enjoy more prestige than any other variety of Ryukyuan to this day. Todas as traduções foram feitas pelos autores deste trabalho. 
de duas línguas como nativo" (p. 56) ${ }^{14}$. Já para Haugen (1953), bilinguismo é quando "o falante de uma língua pode produzir enunciados significativos completos em outra língua" (p. 7) ${ }^{15}$.

A primeira visão, embora seja de entendimento popular entre leigos, é comumente criticada porque, além de não existir um bilíngue ideal, é complexo medir e comprovar que a habilidade de um sujeito em uma língua é idêntica à em outra (MAHER, 2007). Ainda, conforme Grosjean (1982, p. 235) afirma, "um bilíngue desenvolve as quatro habilidades básicas em cada língua (fala, compreensão oral, leitura e escrita) a níveis requeridos pelo ambiente e é raro que um nível idêntico seja necessário para cada habilidade."”.

Já a segunda visão é mais real e próxima do conceito apresentado por Grosjean (1982), que vê o bilíngue como um sujeito que consegue cumprir um objetivo comunicativo diferente em uma língua ou em outras línguas, de acordo com diversos contextos cotidianos.

Percebe-se que os bilíngues utilizam uma língua em uma dada situação e outra(s) língua(s) em outra situação, de acordo com diferentes objetivos e contextos, usufruindo de todos os recursos linguísticos que eles possuem, os quais são considerados um repertório linguístico integrado, que transcende as "fronteiras" das línguas, isto é, translinguagem (translanguaging) (GARCÍA, 2009). Ou seja, o uso das línguas é uma prática socialmente determinada (NORTON, 2000) e o sujeito e o ambiente onde ele se encontra interagem e influem de maneira dinâmica.

Quanto a essa questão, Maher (2007, p. 73) esclarece como segue:

O bilíngue - não o idealizado, mas o de verdade - não exibe comportamentos idênticos na língua $\mathrm{X}$ e na língua $\mathrm{Y}$. A depender do tópico, da modalidade, do gênero discursivo em questão, a depender das necessidades impostas por sua história pessoal e pelas exigências de sua comunidade de fala, ele é capaz de se desempenhar melhor em uma língua do que na outra - e até mesmo de se desempenhar em apenas uma delas em certas práticas comunicativas.

É interessante notar que a habilidade de falar mais de uma língua depende não apenas da vontade do próprio sujeito (como ocorre no contexto educacional de ensino-aprendizagem de línguas estrangeiras), mas, como Maher (2007) frisa, depende do contexto real onde o sujeito vive, mais especificamente, da situação imposta a ele e as suas necessidades em termos de comunicação cotidiana. No caso das situações de migração social e econômica, pode-se dizer que o bilinguismo surge como uma

14 Do original: [the] native-like control of two languages.

15 Do original: the speaker of one language can produce complete meaningful utterances in the other language.

16 Do original: A bilingual develops the four basic skills in each language (speaking, listening, reading, and writing) to the levels required by the environment, and it is rare that an identical level is needed for each skill. 
necessidade para os indivíduos sobreviverem e se adaptarem ao país anfitrião. Diante do exposto, conforme afirma Sakamoto (2000), o bilinguismo deve ser interpretado como um fenômeno peculiar e complexo que possa incluir elementos negativos, ao contrário da imagem positiva convencional.

\section{METODOLOGIA}

\subsection{Abordagem e natureza da pesquisa}

O presente trabalho consiste em uma pesquisa qualitativa (LÜDKE; ANDRÉ, 1986; SILVA, 2017) do tipo etnográfico (BLOMMAERT, 2006; GREEN; BLOOME, 1997 apud SILVA, 2017) na modalidade de história de vida (CRUZ NETO, 2002; SAKURAI, 2012).

No que se refere à história de vida, Cruz Neto (2002, p. 58) afirma que a sua principal função é "retratar as experiências vivenciadas, bem como as definições fornecidas por pessoas, grupos ou organizações". Assim, a história de vida propicia uma riqueza de informações autobiográficas de cada participante que possui experiências vividas naquela comunidade.

Para a presente pesquisa, utilizamos a história de vida tópica ${ }^{17}$ para coletar dados ${ }^{18}$ com enfoque na experiência vivida por cada participante, uma vez que o foco da análise recai sobre a situação atual do uso das línguas.

\subsection{Contexto da pesquisa}

A presente pesquisa foi realizada na Casa Verde, um dos distritos de grande concentração de imigrantes oriundos de Okinawa. Conforme relatado no jornal on-line Utiná Press (s.d.):

No mercado Cantareira e nas imediações, residiam muitas famílias okinawanas, motivo de a vida comunitária gravitar em torno desse espaço comercial, inclusive para a vida social, como festas, namoros e casamentos. Outras famílias dedicavam-se a chácaras, cujos produtos hortifrutigranjeiros eram enviados ao mencionado mercado ou às feiras e quitandas. Essas chácaras concentravam-se mais na zona Leste, na Vila Prudente, na Vila Califórnia, Vila Clara, Diva, Juta e ao longo do rio Tietê, da rodovia Fernão Dias e avenida Anhaia de Mello. E também no bairro Casa Verde, zona norte.

Como o foco deste trabalho é o distrito da Casa Verde, serão discutidos abaixo os motivos que levaram okinawanos a residirem na região. Alguns desses motivos são os preços baixos dos imóveis e aluguéis e proximidade do distrito do Brás, centro de comércio da indústria costureira de São Paulo.

17 Segundo Cruz Neto (2002, p. 58), focaliza uma etapa ou um determinado setor da experiência em questão.

18 Os dados completos sobre a história de vida de cada participante encontram-se em Nakama (2019). 
Os okinawanos usaram a estratégia de procurarem locais que fossem vantajosos do ponto de vista financeiro. O distrito da Casa Verde possui muitos acidentes geográficos, com muitas subidas e descidas, o que tornava o metro quadrado da região barato em comparação com outros locais da cidade na época. Além disso, fica próximo ao aeroporto Campo de Marte. Devido ao barulho dos aviões e à proibição de construção de prédios altos, tinha-se mais um fator para a queda do preço dos imóveis da região.

\subsection{Participantes}

A partir dos contatos iniciais com uma participante desta pesquisa, passou-se a empregar a técnica "bola de neve"19, que consiste em buscar novos contatos (MARGOLIS, 1994 apud SILVA, 2017, p. 33). O processo de criação de uma amostra por bola de neve fundamenta-se em usar a rede social dos indivíduos iniciais para ter acesso ao coletivo. Essa técnica mostrou-se ideal para a presente pesquisa, uma vez que se conseguiu entrevistar imigrantes que em sua maioria não são filiados a nenhuma associação de imigrantes.

Nesta pesquisa, houve 10 participantes. Todos eles são imigrantes de Okinawa e atualmente residem no distrito da Casa Verde. Abaixo segue o perfil de cada participante:

Quadro 1 - Perfil dos participantes da pesquisa

\begin{tabular}{|c|c|c|c|c|c|c|}
\hline $\begin{array}{c}\text { código do } \\
\text { participante }\end{array}$ & gênero & $\begin{array}{l}\text { idade }^{20} \\
\text { (anos) }\end{array}$ & procedência & $\begin{array}{l}\text { escolaridade } \\
\text { / educação } \\
\text { (anos) }\end{array}$ & $\begin{array}{c}\text { ocupação } \\
\text { anterior / atual }\end{array}$ & $\begin{array}{l}\text { tempo de } \\
\text { imigração } \\
\quad \text { (anos) }\end{array}$ \\
\hline A & $\mathrm{m}$ & 80 & Ginowan & 9 (Japão) & $\begin{array}{l}\text { agricultor, costu- } \\
\text { reiro, comerciante } \\
\text { / aposentado }\end{array}$ & 61 \\
\hline B & $\mathrm{f}$ & 80 & Urasoe & 5 (Japão) & $\begin{array}{l}\text { agricultora, costu- } \\
\text { reira, comerciante } \\
\text { / dona de casa }\end{array}$ & 57 \\
\hline $\mathrm{C}$ & $\mathrm{m}$ & 75 & Urasoe & 9 (Japão) & $\begin{array}{l}\text { agricultor, costu- } \\
\text { reiro / aposentado }\end{array}$ & 57 \\
\hline $\mathrm{D}$ & $\mathrm{f}$ & 84 & Kumejima & 9 (Japão) & $\begin{array}{l}\text { guia turística / } \\
\text { dona de casa }\end{array}$ & 57 \\
\hline $\mathrm{E}$ & $\mathrm{f}$ & 83 & Nanjō & 9 (Japão) & $\begin{array}{l}\text { agricultora / } \\
\text { dona de casa }\end{array}$ & 63 \\
\hline
\end{tabular}

19 Essa técnica é definida por Margolis (1994, p. 20) como "uma técnica de amostragem não aleatória, por ser uma forma reconhecida de contatar populações 'escondidas' ” (apud SILVA, 2017, p. 33).

20 No momento de março de 2019. 


\begin{tabular}{|c|c|c|c|c|c|c|}
\hline $\begin{array}{c}\text { código do } \\
\text { participante }\end{array}$ & gênero & $\begin{array}{c}\text { idade } \\
\text { (anos) }\end{array}$ & procedência & $\begin{array}{c}\text { escolaridade } \\
\text { / educação } \\
\text { (anos) }\end{array}$ & $\begin{array}{c}\text { ocupação } \\
\text { anterior / atual }\end{array}$ & $\begin{array}{c}\text { tempo de } \\
\text { imigração } \\
\text { (anos) }\end{array}$ \\
\hline $\mathrm{F}$ & $\mathrm{f}$ & 61 & Urasoe & 11 (Brasil) & $\begin{array}{c}\text { agricultora / } \\
\text { comerciante }\end{array}$ & 57 \\
\hline $\mathrm{G}$ & $\mathrm{m}$ & 66 & Yonabaru & $\begin{array}{c}\text { 1 (Japão) } \\
\text { (Brasil) }\end{array}$ & comerciante & 56 \\
\hline $\mathrm{H}$ & $\mathrm{m}$ & 69 & Urasoe & 6 (Japão) & $\begin{array}{c}\text { agricultor / } \\
\text { comerciante }\end{array}$ & 57 \\
\hline $\mathrm{I}$ & $\mathrm{f}$ & 72 & Ōzato & $\begin{array}{c}3 \text { (Japão) } \\
\text { (Brasil) }\end{array}$ & $\begin{array}{c}\text { costureira / } \\
\text { aposentada }\end{array}$ & 63 \\
\hline $\mathrm{J}$ & $\mathrm{f}$ & 91 & Nago & 3 (Brasil) & $\begin{array}{c}\text { agricultora / } \\
\text { aposentada }\end{array}$ & 87 \\
\hline
\end{tabular}

Fonte: autoria própria

Notas: "m" representa masculino.

"f" representa feminino.

Conforme afirma Sakurai (2012, p. 118), a narrativa é influenciada pela maneira como o entrevistador percebe a fala do entrevistado. Ainda, a narrativa depende de vários fatores, tais como o modo de falar do entrevistado e outros hábitos culturais; relacionamento com o entrevistador; e contexto social (SAKURAI, 2012, p. 22). Dessa maneira, o entrevistador ocupa papel importante para a investigação nesta pesquisa. Um dos autores do presente trabalho é filho de imigrantes oriundos de Okinawa e entende suficiente o uchināguchi para fazer as entrevistas.

\subsection{Instrumentos e procedimento para a coleta de dados}

Para a coleta de dados, foram realizadas entrevistas com anotações e gravações seguindo um roteiro preparado antecipadamente (cf. NAKAMA, 2019), com o intuito de compreender a situação atual do uso das línguas pelos imigrantes de primeira geração de Okinawa.

Conforme Neto (2002), a aplicação de entrevista é adequada para obter as narrativas acerca das experiências dos próprios entrevistados. Neto (2002, p. 59) afirma que o destaque nessa metodologia de pesquisa é a entrevista em profundidade, permitindo ao participante retomar sua vivência de forma retrospectiva e fornece um olhar cuidadoso sobre a própria vivência ou sobre determinado fato. Ainda, Sakurai $(2012$, p. 111) afirma que, no processo de entrevista, o entrevistador assume o papel de um guia enquanto o narrador conta sua história.

Para a presente pesquisa, o roteiro de perguntas (cf. NAKAMA, 2019) compõe-se de duas partes: (i) o perfil dos participantes e (ii) a situação do uso das línguas pelos participantes. A primeira parte é composta de 25 perguntas, as quais foram elaboradas 
com o intuito de obter o perfil dos participantes, tais como o ano, a idade que imigraram e o tempo de permanência no Brasil. Já a segunda parte, na qual é formada por 9 perguntas abertas e em escala, é voltada para investigar a situação atual do uso das línguas pelos participantes.

As entrevistas foram realizadas na residência de cada participante ou de um parente do mesmo no período de 6 de março a 9 de maio de 2019. Para sanar algumas dúvidas decorrentes das respostas e narrativas obtidas na primeira sessão de entrevista, alguns participantes foram entrevistados mais de uma vez. As entrevistas foram gravadas em áudio com permissão antecipada dos participantes por meio do termo de consentimento livre e esclarecido (cf. NAKAMA, 2019).

\subsection{Procedimento para a análise dos dados}

O procedimento para a análise dos dados foi realizado como segue:

a) coleta de dados por meios de entrevistas gravadas em áudio com anotações, e escritas em formulário;

b) transcrição ${ }^{21}$ dos dados oriundos das entrevistas;

c) mapeamento e análise do perfil dos participantes;

d) sistematização acerca da situação do uso das línguas pelos participantes;

e) identificação e descrição acerca do uso das línguas pelos participantes baseadas nos dados transcritos; e

f) análise e interpretação sobre as relações entre o perfil e a situação do uso das línguas.

\section{ANÁLISE E DISCUSSÃO DE DADOS}

Na seção 4.1, serão apresentados os resultados da análise dos dados referentes ao perfil dos participantes. Em seguida, na seção 4.2, será discutida a situação de uso de línguas pelos participantes desta pesquisa, além do discurso interior ${ }^{22}$.

\subsection{Análise do perfil dos participantes}

Foram 10 participantes, todos com idade acima de 60 anos e com média de 76 anos. Passou-se mais de meio século desde que imigraram para o Brasil, com permanência média de 62 anos.

21 Quanto aos dados transcritos completos das entrevistas de cada participante, vide Nakama (2019).

22 Trata-se de um pensamento expresso em palavras. Consiste na tradução do pensamento em palavras, ou seja, a fala interioriza-se no pensamento (VIGOTSKI, 2001). 
Quadro 2 - Classificação dos participantes conforme seu perfil

\begin{tabular}{|c|c|c|c|c|c|}
\hline grupo & $\begin{array}{c}\text { código do } \\
\text { participante }\end{array}$ & gênero & $\begin{array}{c}\text { idade }^{23} \\
\text { (anos) }\end{array}$ & $\begin{array}{l}\text { tempo de } \\
\text { imigração } \\
\text { (anos) }\end{array}$ & $\begin{array}{c}\text { escolaridade / } \\
\text { educação (anos) }\end{array}$ \\
\hline \multirow{7}{*}{1} & A & $\mathrm{m}$ & 80 & 61 & 9 (Japão) \\
\hline & B & $\mathrm{f}$ & 80 & 57 & 5 (Japão) \\
\hline & $\mathrm{C}$ & $\mathrm{m}$ & 75 & 57 & 9 (Japão) \\
\hline & $\mathrm{D}$ & $\mathrm{f}$ & 84 & 57 & 9 (Japão) \\
\hline & E & $\mathrm{f}$ & 83 & 63 & 9 (Japão) \\
\hline & $\mathrm{H}$ & $\mathrm{m}$ & 69 & 57 & 9 (Japão) \\
\hline & $\mathrm{J}^{24}$ & $\mathrm{f}$ & 91 & 87 & 3 (Brasil) \\
\hline \multirow{3}{*}{2} & $\mathrm{~F}$ & $\mathrm{f}$ & 61 & 57 & 11 (Brasil) \\
\hline & G & $\mathrm{m}$ & 66 & 56 & $\begin{array}{l}1 \text { (Japão) } \\
5 \text { (Brasil) }\end{array}$ \\
\hline & I & $\mathrm{f}$ & 72 & 63 & $\begin{array}{l}3 \text { (Japão) } \\
4 \text { (Brasil) }\end{array}$ \\
\hline
\end{tabular}

Fonte: autoria própria

Notas: "m" representa masculino

"f" representa feminino

Conforme o perfil dos participantes da pesquisa, pôde-se dividi-los em dois grupos. Os participantes do primeiro grupo vieram para o Brasil já adolescentes ou adultos e sua principal preocupação cotidiana é, ou era, trabalhar bastante para proporcionar uma vida melhor para família, filhos ou comunidade. Assim, eles apresentam integração limitada com a sociedade brasileira e sofrem dificuldade com a língua portuguesa para realizar suas atividades com pessoas que falem somente em português. De modo geral, falam apenas em uchināguchi ou quase sempre em uchināguchi no dia a dia.

23 No momento de março de 2019.

24 A participante J é a única que imigrou para o Brasil antes da Segunda Guerra Mundial. Como tal, sofreu influência dos costumes da época. Imigrou com cinco anos, estudou a língua japonesa no Brasil e viveu em comunidade rural de nikkei. Muitos com quem convivia eram japoneses de outras províncias e, por isso, acostumou-se a conversar em japonês. Como veio para o Brasil com cinco anos e estudou no Brasil, era de se esperar que pertencesse ao segundo grupo de participantes, mas ela está no primeiro grupo. Isso se deve ao fato de que, apesar de ter vindo muito nova e ter estudado no Brasil, tem dificuldade em conversar em português, restringindo o uso dessa língua aos filhos e evita comunicação com brasileiros em geral. 
Já os participantes do segundo grupo imigraram ainda novos e puderam estudar em escolas do Brasil. Assim, eles apresentam integração completa com a sociedade brasileira e não enfrentam barreira linguística. Falam português, uchināguchi ou mistura dessas línguas no cotidiano. Morales (2008) frisa que a idade e o contexto em que o indivíduo adquire a(s) língua(s) são determinantes na configuração cognitiva (MORALES, 2008, p. 152-3).

\subsection{Uso de línguas dos participantes}

\subsubsection{Uso de línguas dos participantes conforme o interlocutor}

De acordo com a tabela 1, nota-se que aparecem duas regiões de concentração. Uma na parte superior à esquerda, com as relações mais próximas com maior uso de uchināguchi e outra na parte inferior à direita, com relações mais distantes com maior uso do português.

Tabela 1 - Uso de línguas dos participantes conforme o interlocutor

\begin{tabular}{|c|c|c|c|c|c|c|c|}
\hline língua & irmãos & amigos & cônjuge & filhos & netos & outros & TOTAL \\
\hline U & 2 & 1 & 1 & - & - & - & 4 \\
\hline QU & 5 & 4 & 2 & - & - & - & $\mathbf{1 1}$ \\
\hline UJ & - & - & - & 1 & - & - & $\mathbf{1}$ \\
\hline JU & - & 1 & - & - & - & - & $\mathbf{1}$ \\
\hline J & - & - & - & 1 & - & - & $\mathbf{1}$ \\
\hline QJ & - & - & - & 1 & - & - & $\mathbf{1}$ \\
\hline JP & - & - & - & - & - & - & $\mathbf{0}$ \\
\hline PJ & - & - & - & - & - & - & $\mathbf{0}$ \\
\hline P & - & - & 1 & 1 & 4 & 1 & $\mathbf{7}$ \\
\hline QP & 1 & 2 & 1 & - & - & - & $\mathbf{4}$ \\
\hline outros & & 1 & 1 & 3 & - & - & $\mathbf{5}$ \\
\hline TOTAL & $\mathbf{8}$ & $\mathbf{9}$ & $\mathbf{6}$ & $\mathbf{7}$ & $\mathbf{4}$ & $\mathbf{1}$ & \\
\hline
\end{tabular}

Fonte: autoria própria

Notas:

$\mathrm{U}$ representa apenas uchināguchi.

QU representa quase sempre uchināguchi.

UJ representa uchināguchi e japonês com predominância de uchināguchi.

JU representa uchināguchi e japonês com predominância de japonês.

$\mathrm{J}$ representa apenas japonês.

QJ representa quase sempre japonês. 
JP representa japonês e português com predominância de japonês.

PJ representa japonês e português com predominância de português.

$\mathrm{P}$ representa apenas português.

QP representa quase sempre português.

A coluna "outros" refere-se a sobrinhos.

A linha "outros" inclui duas combinações de línguas: a primeira é mistura de português

e uchināguchi; a segunda é mistura de português, uchināguchi e japonês.

Quanto à língua usada para se comunicar, o primeiro grupo referido na seção 4.1 geralmente usa exclusivamente ( 4 casos $)^{25}$ ou quase sempre (11 casos) uchināguchi (cf. $\mathrm{n}^{0}$ total da tabela 1). A língua japonesa é geralmente usada por este grupo de alguma forma, exclusivamente ( 1 caso) ou quase sempre (1 caso), como estratégia de comunicação para manter conversação com seus interlocutores (japoneses) porque eles não compreendem uchināguchi. Abaixo seguem alguns excertos dos participantes do primeiro grupo:

(1) Japonês misturado com uchināguchi, usando mais uchināguchi com os filhos. É isso. Ah, estes [netos] ${ }^{26}$ como não entendem [japonês], então é a língua brasileira mesmo. $^{27}\left(\mathrm{PA}^{28}\right.$, entrevista, 07/03/2019)

(2) Com os amigos, é japonês. Com papai e mamãe é a língua de Okinawa. Com os irmãos também é a língua de Okinawa. Com o cônjuge é a língua de Okinawa. Com os filhos é misturado, uchināguchi com a língua do Brasil. Com os netos é um pouco da língua do Brasil, mas eu não sei [falar português]. (PB, entrevista, 09/05/2019)

(3) Quanto ao casal, é uchināguchi, né. Mas, no caso dos filhos, uso a língua japonesa. (PC, entrevista, 07/03/2019)

Os participantes acima citam que quase sempre falam em uchināguchi. No entanto, com pessoas que não falam uchināguchi, eles precisam mudar de língua para serem compreendidos (GROSJEAN, 1982). Assim, mesmo sentindo-se receosos em não proferir um discurso em que sejam compreendidos satisfatoriamente, veem-se obrigados a falar em uma língua (MAHER, 2007) em que não se sentem confortáveis. Conforme afirma Azuma (2000, p. 14-15), nota-se que o uso das línguas depende, também, da atitude com relação à língua além do interlocutor e do contexto.

Com relação ao uso da língua portuguesa, a maioria dos casos refere-se aos participantes do segundo grupo: apenas português (7 casos), quase sempre português (4 casos) e outros (5 casos, que incluem mistura de português e uchināguchi e mistura de

25 Os números entre parênteses indicam os valores que aparecem nos quadros.

26 Os símbolos [ e ] indicam as palavras acrescentadas para que o texto fique compreensível.

27 Os excertos foram traduzidos para o português pelos autores. Omitiram-se as falas originais em função de espaço deste artigo. Quanto à transcrição íntegra, vide Nakama (2019).

28 A letra "P" significa participante e a letra "A" corresponde ao código do participante. 
português, uchināguchi e japonês) (cf. $\mathrm{n}^{\circ}$ total da tabela 1). No entanto, para conversar com os netos, como foi relatado pelo participante A acima (cf. excerto [1]), por exemplo, é usada a língua portuguesa mesmo sendo participante do primeiro grupo. Seguem dois excertos relatando a mistura de línguas:

(4) Marido? Português, japonês e uchināguchi misturados. Com a filha? Também tudo misturado. (PF, entrevista, 08/03/2019)

(5) [Quando falo com a família e com os amigos] é misturado né? [Com os irmãos] é português. [Com os amigos] é português. [Com a esposa] é meio a meio, misturado. Uchināguchi e português. [Com a filha] é uchināguchi e português. (PG, entrevista, 08/03/2019)

Com relação aos interlocutores, os participantes citaram que se comunicam mais com irmãos (9 casos), amigos ( 8 casos), filhos ( 7 casos), cônjuge (6 casos) e netos (4 casos) (cf. tabela 1). Para esse último caso, destaca-se a distância geracional, que faz com que seja usada apenas a língua portuguesa ou mistura da língua portuguesa com uchināguchi (GARCÍA, 2009).

Pode-se notar pela tabela 1 que, para relações mais próximas, como a de irmãos, a tendência é de usar a língua materna. Quando as relações ficam mais distantes, como a de netos e sobrinhos, tende-se a usar a língua local porque a comunicação em $u c h i n \bar{a}-$ guchi torna-se inviável.

\subsubsection{Uso de línguas conforme o contexto}

Conforme afirma Grosjean (1982), nesta pesquisa também se revelou que a escolha da língua a ser usada depende do interlocutor do participante e da preferência ou facilidade do uso de língua de acordo com o contexto. A tabela 2 resume o uso de línguas conforme o contexto.

Tabela 2 - Uso de línguas conforme o contexto

\begin{tabular}{|l|c|c|c|c|c|}
\hline contexto & uchinäguchi & japonês & português & outros & TOTAL \\
\hline em casa & 4 & 1 & 4 & - & $\mathbf{9}$ \\
\hline na vizinhança & 4 & 2 & 5 & 3 & $\mathbf{1 4}$ \\
\hline com okinawanos & 3 & - & 1 & 2 & $\mathbf{6}$ \\
\hline com japoneses & - & 5 & 1 & - & $\mathbf{6}$ \\
\hline com não japoneses & - & - & 6 & - & $\mathbf{6}$ \\
\hline no trabalho & - & 1 & 3 & - & $\mathbf{4}$ \\
\hline
\end{tabular}




\begin{tabular}{|l|c|c|c|c|c|}
\hline contexto & uchināguchi & japonês & português & outros & TOTAL \\
\hline outros & - & - & 4 & - & 4 \\
\hline TOTAL & 11 & 9 & 24 & 5 & \\
\hline
\end{tabular}

Fonte: autoria própria

Abaixo seguem alguns excertos:

(6) Em casa é a língua de Okinawa. Na vizinhança e arredores, no caso de não japoneses, somente "Bom dia. Boa tarde". É porque não consigo falar mais que isso. Com os vizinhos, em japonês. Quando encontro com brasileiros não falo nada porque não consigo falar. Com pessoas de Okinawa, é a língua de Okinawa. (PB, entrevista, 09/05/2019)

(7) Em casa é lógico que é uchināguchi, né. Nas redondezas? Como nas redondezas só têm brasileiros, é português. (PC, entrevista, 07/03/2019)

(8) [Em casa] é a língua de Okinawa, viu! Uchināguchi, nas redondezas é uchināguchi sempre. [Na associação dos okinawanos] lá também é uchināguchi. (PE, entrevista, 07/03/2019)

(9) Nos arredores é português, em geral, em português. Misturo uchināguchi e português. Misturo todos, uchināguchi, português e japonês. (PH, entrevista, 05/05/2019)

(10) Nos arredores, às vezes, falo japonês, português, tudo varia, depende da pessoa. [...] Aqui por perto, com okinawanos [...] se forem issei (primeira geração) é uchināguchi. E se forem $n$ nsei $^{29}$ (segunda geração), é português. (PI, entrevista, 06/05/2019)

Os excertos acima evidenciam que, conforme afirma Azuma (2000, p. 14), o bilinguismo não é uma ocorrência estática como o ponto de chegada (sabendo controlar duas línguas perfeitamente), mas sim uma ocorrência dinâmica, que se adequa às mais variadas condições, tais como nível de formalidade, conhecimento linguístico do interlocutor, intimidade entre os interlocutores e o contexto em que se insere o tópico.

No primeiro grupo, a língua preferida do participante é uchināguchi e como cônjuge, irmãos e amigos falam uchināguchi, a língua citada é a mesma. No caso de vizinhança, como os interlocutores geralmente falam apenas português, essa é a única língua que permite a comunicação, mesmo que o participante tenha dificuldade com a língua. Para os participantes do segundo grupo, a escolha da língua é mais flexível, dependendo geralmente do domínio social ${ }^{30}$, conforme relatado pela participante I (cf. excerto [10]).

29 Todos os termos em japonês e okinawano foram transcritos para o alfabeto latino de acordo com o sistema Hepburn, inclusive aqueles que possuem forma aportuguesada.

30 Por exemplo, pode-se referir à família, escola, igreja, trabalho, rua e amizades (FISHMAN, 1972). 


\subsubsection{Discurso interior}

Com relação ao discurso interior (VIGOTSKI, 2001), ou seja, as atividades linguísticas para o pensamento não verbalizado, nota-se que existe uma diferença nítida entre os grupos.

Para o primeiro grupo, o discurso interior é em uchināguchi, ou seja, na língua materna deles, como verificado nos excertos seguintes:

(11) É uchināguchi. (PC, entrevista, 07/03/2019)

(12) Quanto a isso [discurso interior] é quase sempre uchināguchi. (PD, entrevista, 07/03/2019)

(13) É uchināguchi, não é mesmo? (PE, entrevista, 07/03/2019)

Para o segundo grupo, apesar de a língua materna ser uchināguchi e como os integrantes deste grupo vieram para o Brasil ainda novos, o discurso interior geralmente muda para o português, como verificado nos excertos abaixo:

(14) Português, geralmente. (PF, entrevista, 08/03/2019)

(15) Português. (PG, entrevista, 08/03/2019)

No caso da participante I, mesmo sendo do segundo grupo, seu discurso interior é predominantemente o da língua materna:

(16) É mais uchināguchi. (PI, entrevista, 06/05/2019)

É interessante notar que, no caso da participante I, o fato de conseguir se comunicar sem nenhuma dificuldade na língua portuguesa não foi suficiente para alterar a língua de discurso interior, mantendo a língua materna.

\section{CONSIDERAÇÕES FINAIS}

O objetivo deste trabalho foi investigar a situação sociolinguística de uso das línguas pelos okinawanos de primeira geração que imigraram para o Brasil e que vivem atualmente no distrito da Casa Verde na capital do estado de São Paulo, conforme descrito na seção introdutória. Para a consecução desse objetivo, uma pergunta norteou esta pesquisa: Quais as línguas e em que contexto os imigrantes de primeira geração de Okinawa as usam no dia a dia?

Na seção 4 sobre análise e discussão dos dados, verificou-se que foi útil dividir os participantes em dois grupos: 
1) primeiro grupo cujos participantes apresentam integração limitada com a sociedade brasileira e sofrem dificuldades para se comunicar na língua portuguesa; e

2) segundo grupo cujos participantes apresentam integração completa com a sociedade brasileira e não enfrentam barreiras linguísticas.

Quanto à resposta à pergunta de pesquisa, os participantes do primeiro grupo, que vivem na comunidade okinawana, usam uchinäguchi com parentes de mesma geração, como irmãos, e cônjuge. Assim, o discurso interior também é em uchināguchi. Quando o interlocutor não consegue comunicar-se em uchināguchi, a língua com que melhor conseguem se comunicar é o japonês. O português é usado caso não seja possível estabelecer comunicação nem em uchināguchi nem em japonês, por exemplo, com netos, sobrinhos ou brasileiros em geral. Os participantes desse grupo, então, mudam de uma língua para outra de acordo com o contexto e os interlocutores, mais especificamente, levando em consideração o conhecimento linguístico de seu interlocutor (GROSJEAN, 1982, 2008).

Já os participantes do segundo grupo, que apresentam integração completa com a sociedade brasileira, usam uchināguchi ou português, ou misturam essas duas línguas, de acordo com o conhecimento linguístico de seu interlocutor (translanguaging de García [2009]). Porém, dão preferência à língua portuguesa por usarem-na com mais frequência. $\mathrm{O}$ uso do japonês restringe-se aos japoneses que não entendem uchināguchi. O discurso interior é predominantemente em português. Os participantes desse grupo, então, utilizam as línguas de forma mais flexível a depender dos interlocutores e do contexto (GROSJEAN, 1982, 2008).

Conforme visto neste estudo, os participantes desta pesquisa imigraram para o Brasil e vivem aqui há mais de meio século. No entanto, independentemente da idade que imigraram, todos se declararam na entrevista como sendo uchinānchu (okinawanos) e não como japoneses nem como nikkei (descendentes de japoneses). Desse modo, verifica-se que mantêm até hoje forte ligação sentimental com sua terra natal, preservando a identidade okinawana, independentemente do uso que fazem da língua ou do tempo de permanência no Brasil.

Com vistas à completude deste estudo, estamos cientes de que se deve coletar mais dados e analisá-los mais detalhadamente para que se possa elucidar, de forma holística, a situação do uso de línguas pela primeira geração de imigrantes okinawanos no Brasil. Mesmo assim, esperamos que este trabalho possa contribuir, de forma modesta, para o desenvolvimento da área de Sociolinguística, mais especificamente, bilinguismo no qual se envolve a língua de Okinawa, uchināguchi.

A partir do que foi pesquisado, diversas outras questões podem ser elencadas. Especialmente em relação ao uchināguchi, poderia ser estudado como os descendentes dos imigrantes de Okinawa fazem uso desta língua nas diversas localidades em que se estabeleceu uma comunidade uchinānchu. 


\section{REFERÊNCIAS BIBLIOGRÁFICAS}

AZUMA, S. Bilingualism. Tōkyō: Kōdansha, 2000.

BLOMMAERT, J. Ethnographic fieldwork: a beginner's guide. London, 2006. Não publicado.

BLOOMFIELD, L. Language. Holt, Rinehart and Winston, 1933.

CRUZ NETO, O. O trabalho de campo como descoberta e criação. In: MINAYO, M. C. de S.; DESLANDES, S. F.; CRUZ NETO, O.; GOMES, R. (org.). Pesquisa Social: teoria, método e criatividade. 21. ed., Petropólis: Editora Vozes, 2002. p. 51-66.

FISHMAN, J. A. Domains and the relationships between micro- and macrosociolinguistics. In: GUMPERZ, J.; HYMES, D. (ed.). Directions in sociolinguistics: the ethnography of communication. New York, NY: Holt, Rinehart, and Winston, 1972. p. 435-453.

GARCÍA, O. Education, Multilingualism, and Translanguaging in the 21st Century. In: SKUTNABB-KANGAS, T.; PHILlIPSON, R.; MOHANTY, A. K.; PANDA, M. (ed.). Social Justice through Multilingual Education. Bristol, UK: Multilingual Matters, p. 140-158, 2009.

GREEN, J. L.; BLOOME, D. Ethnography and ethnographers of and in education: a situated perspective. In: FLOOD, J.; HEATH, S.; LAPP, D. (ed.). Handbook of research on teaching literacy through the communicative and visual arts. New York, NY: Simon \& Schuster Macmillan, 1997. p. 181-202.

GROSJEAN, F. Life with two languages: an introduction to bilingualism. Cambridge, Massachusetts: Harvard University Press, 1982.

. Studying Bilinguals. Oxford, UK: Oxford University Press, 2008.

HAUGEN, E. The Norwegian language in America: a study in bilingual behavior. University of Pennsylvania Press, 1953.

HEINRICH, P.; MIYARA, S.; SHIMOJI, M. Handbook of the Ryukyuan Languages. Berlin: Walter de Gruyter, 2015.

ISHIKAWA, T. Okinawaken niokeru shutsu imin no rekishi oyobi shutsu imin yōinron (History emigration from Okinawa Prefecture and some accounts on emigration motives). Immigration Studies. n. 1, p. 11-30, 2005.

JORNAL UTINÁ PRESS. Em busca da identidade okinawana. Disponível em: http://www. utinapress.com.br/mio_28.html. Acesso em: 03 de abr. de 2019.

LÜDKE, M.; ANDRÉ, M. E. D. A. Pesquisa em educação: abordagens qualitativas. São Paulo: EPU, 1986.

MAHER, T. M. Do casulo ao movimento: a suspensão das certezas na educação bilíngue e intercultural. In: CAVALCANTI, M. C.; BORTONI-RICARDO, S. M. (org.). Transculturalidade, linguagem e educação. Campinas, SP: Mercado de Letras, 2007. p.67-94.

MARGOLIS, M. L. Little Brazil: imigrantes brasileiros em Nova York. Tradução de Araújo, L.; Bugel, T. Campinas, SP: Papirus, 1994. 
MORALES, M. Cem anos de imigração japonesa no Brasil: o japonês como língua estrangeira. 2008. 313 f. Tese (Doutorado em Linguística) - Programa de Pós-Graduação em Linguística, Universidade de São Paulo, São Paulo, 2008.

MORI, L. Os descendentes que preservaram no Brasil uma língua que quase não se fala mais no Japão. São Paulo: BBC Brasil, 2018. Disponível em: https:/www.bbc.com/portuguese/ brasil-42775209. Acesso em: 15 jan. 2019.

MORIMOTO, T. Okinawa to 'kenkeijin' to no chūtai (Laços entre Okinawa e 'okinawanos'). In: MORIMOTO, T.; NEGAWA, S. (org.). Transnacional na 'nikkeijin' no kyōiku, gengo, bunka (Educação, linguagem e cultura pelos descendentes de japoneses transnacionais). Tōkyō: Akaishi shoten, 2012.

MOSELEY, C. (ed.). Atlas of the World's Languages in Danger. 3. ed., Paris: UNESCO Publishing, 2010. Disponível em: http://www.unesco.org/culture/en/endangeredlanguages/ atlas. Acesso em: 15 jan. 2019.

NAKAMA, E. Um estudo da situação sociolinguística da primeira geração de imigrantes okinawanos que vivem no distrito da casa verde na cidade de São Paulo. 2019. 116 f. Trabalho de conclusão de curso (Graduação em Letras-Japonês) - Instituto de Letras. Universidade de Brasília, Brasília, 2019.

NORTON, B. Identity and language learning: gender, ethnicity and educational change. Essex, England: Pearson Education Limited, 2000.

OKINAWA DAI HYAKKA JITEN KANKŌ JIMUKYOKU-HEN (org.). Okinawa dai hyakka jiten (Grande enciclopédia de Okinawa). Naha: Okinawa Times Sha, 1983.

OKINAWA-KEN KŌRYŪ SUISHIN-KA. Okinawa to imin no rekishi (Okinawa e a história de imigração). Disponível em: https://www.pref.okinawa.jp/toukeika/so/topics/topics457. pdf. Acesso em: 14 dez. 2018.

PIRES, R. Os outros japoneses: festivais e construção identitária na comunidade okinawana da cidade de São Paulo. 2016. 326 f. Tese (Doutorado em História) - Faculdade de Filosofia Letras e Ciências Humanas. Universidade de São Paulo, São Paulo, 2016.

SAKAMOTO, M. Bilingualism to bilingual kyōiku: kokusaijin ikusei ni muketa riron to jissen (Bilinguismo e educação bilíngue: teoria e prática para o desenvolvimento das pessoas internacionais). Miyagi kyōiku daigaku kokusai rikai kyōiku kenkyū center nenpō (Anais do Research Center for Education in International Understanding of Miyagi University of Education), v. 5, p. 1-7, 2000.

SAKURAI, A. Life story ron (Teoria sobre a história de vida). Tōkyō: Kōbundō, 2012.

SILVA, S. de S. Do estado plurinacional da Bolívia para o Brasil: um estudo da situação sociolinguística de um grupo de imigrantes bolivianos que vivem na região metropolitana de São Paulo. 2017. 324 f. Tese (Doutorado em Letras e Linguística) - Faculdade de Letras. Universidade Federal de Goiás, Goiânia, 2017.

VIGOTSKI, L. S. A construção do pensamento e da linguagem. Tradução de Paulo Bezerra. São Paulo: Martins Fontes, 2001 (obra original publicada em russo em 1934). 